\title{
DR-37
}

\section{SYNTHESIS, CHARACTERIZATION AND LUMINESCENT PROPERTIES OF MG- AND CR-DOPED ALUMINA CERAMICS}

\author{
E. I. Frolov, ${ }^{1,2}$ S. V. Zvonarev, ${ }^{1}$ Yu V. Moshchenskij, ${ }^{2}$ K. Yu. Chesnokov, ${ }^{3}$ A. V. Chukin, ${ }^{1}$ \\ A. V. Abramov, ${ }^{1}$ V. Yu. Churkin, ${ }^{1}$ N. V. Obvintseva ${ }^{1}$ \\ ${ }^{1}$ Ural Federal University of the first President of Russia B. N. Yeltsin. \\ Mira St., 19. Ekaterinburg, 620002, Russia. \\ ${ }^{2}$ Samara State Technical University, 244 Mologvardeyskaya St., Samara, 443100, Russia. \\ ${ }^{3}$ Institute of Solid State Chemistry, Ural Branch, Russian Academy of Sciences. \\ 91 Pervomaiskaya St., Ekaterinburg, 620990, Russia. \\ E-mail: s.v.zvonarev@urfu.ru
}

\begin{abstract}
Experimental research of luminescent properties of oxide ceramics is of great interest for understanding specific features of structural properties and forecasting new functional materials properties since electron and quantum effects play an important role in occurrence of various physical effects such as electrical conductivity, electron emission, luminescence, electrical breakdown, and many others. In this regard, the aim of this paper is the synthesis, characterization and studying of luminescent properties of $\mathrm{Mg}$ - and $\mathrm{Cr}$-doped alumina ceramics.

At the first stage of the synthesis the initial porous matrixes in a compact form were obtained with the cold static pressing method $(0.4 \mathrm{GPa})$ of high purity $(99.7 \%)$ commercial alumina oxide nanopowder. At the second stage compact thermal tempering at the temperature of $450 \mathrm{C}$ for 2 hours was conducted. $\mathrm{A} 12 \mathrm{O} 3$ porous matrixes were impregnated in a solution of Magnesium (II) nitrate hexahydrate (the $\mathrm{Mg}$ concentration in the range of 0.1-6.85 wt. \%) and Chromium (III) nitrate nonahydrate (the $\mathrm{Cr}$ concentration in the range of $0.01-9.78 \mathrm{wt} . \%$ ) at a room temperature for 1 hour. The doped samples sintering was conducted to create ceramics within the temperature ranges corresponded to more stable polymorphic modifications of the oxide compositions under consideration, both in air in an electric furnace and under vacuum using a high-temperature vacuum $(0.013 \mathrm{~Pa})$ electric furnace STVE 9/18 for 4 hours.
\end{abstract}

The investigation of the heating process for changes in the internal thermal potential in compacts, both of pure aluminum oxide and doped with $\mathrm{Mg}^{+2} \mathrm{U} \mathrm{Cr}^{+3}$ cations from salt solutions, obtained by sintering in various conditions was conducted employing differential scanning calorimetry (DSC). The samples characterization was held by XRD and XRF analyzes methods. The alumina initial matrix doping leads to a new phase formation after high temperature sintering, $\mathrm{MgAl} 2 \mathrm{O} 4$ spinel in particular. The decrease in dopant content leads to the decrease in quantitative content of the specified phase in ceramic. The annealing temperature growth within the range of $1500-1700{ }^{\circ} \mathrm{C}$ is accompanied by quantitative content increase in spinel phase in ceramic by about $30 \%$. The obtained results are confirmed by the quantitative element analysis data. Within the sintering temperature ranges described above $\mathrm{Mg}$ content growth occurs within the range of 4.8 to $6.5 \mathrm{wt}$. \%. For Cr-doped alumina ceramics a sintering temperature growth leads to lowering of dopant content in the sample. Moreover, the less $\mathrm{Cr}$ concentration is during doping the larger its proportion is found in the sample after sintering. So, at the maximal sintering temperature the $25-34 \%$ of 1 wt. \% of Cr during doping is registered in the sample and 70-80\% of $0.1 \%$ wt. of chromium.

It is shown that $\mathrm{Mg}$ doping leads to a new luminescence band formation in PCL spectra with its maximum at $518 \mathrm{~nm}$. Compared to $\mathrm{Mg}$-doped alumina ceramics a doping with $\mathrm{Cr}$ leads to a formation of almost an isolated high-intensity band with its maximum at $693 \mathrm{~nm}$ in a PCL spectrum. An increase in the dopant concentration leads to an increase in the PCL intensity of the dopant center in Mg-doped alumina ceramic and a decrease in the PCL intensity of the dopant center in Cr-doped alumina ceramic. 